\title{
PAX5-positive T-cell anaplastic large cell lymphomas associated with extra copies of the PAX5 gene locus
}

\author{
Andrew L Feldman ${ }^{1}$, Mark E Law ${ }^{1}$, David J Inwards ${ }^{2}$, Ahmet Dogan ${ }^{1}$, Rebecca F McClure \\ and William R Macon ${ }^{1}$ \\ ${ }^{1}$ Department of Laboratory Medicine and Pathology, Mayo Clinic, Rochester, MN, USA and ${ }^{2}$ Division of \\ Hematology, Mayo Clinic, Rochester, MN, USA
}

\begin{abstract}
Cell lineage is the major criterion by which lymphomas are classified. Immunohistochemistry has greatly facilitated lymphoma diagnosis by detecting expression of lineage-associated antigens. However, loss or aberrant expression of these antigens may present diagnostic challenges. Anaplastic large cell lymphoma is a T-cell lymphoma that shows morphologic and phenotypic overlap with classical Hodgkin's lymphoma, which is a tumor of B-cell derivation. Staining for the B-cell transcription factor, paired box 5 (PAX5), has been suggested to be helpful in this differential, as it is positive in most classical Hodgkin's lymphomas, but absent in anaplastic large cell lymphomas. In this study we report four systemic T-cell anaplastic large cell lymphomas that were positive for PAX5 by immunohistochemistry, with weak staining intensity similar to that observed in classical Hodgkin's lymphoma. All diagnoses were confirmed by a combination of morphologic, phenotypic, and molecular criteria. Three cases were anaplastic lymphoma kinase (ALK) negative and one was ALK positive. PAX5 immunohistochemistry was negative in 198 additional peripheral T-cell lymphomas, including 66 anaplastic large cell lymphomas. Unexpectedly, although PAX5 translocations were absent, all evaluable PAX5positive anaplastic large cell lymphomas showed extra copies of the PAX5 gene locus by fluorescence in situ hybridization (FISH). In contrast, only $4 \%$ of PAX5-negative peripheral T-cell lymphomas had extra copies of PAX5. We conclude that aberrant expression of PAX5 occurs rarely in T-cell anaplastic large cell lymphomas, and may be associated with extra copies of the PAX5 gene. PAX5-positive lymphomas with morphologic features overlapping different lymphoma types should be evaluated with an extensive immunohistochemical panel and/or molecular studies to avoid diagnostic errors that could lead to inappropriate treatment. As PAX5 overexpression causes T-cell neoplasms in experimental models, PAX5 may have contributed to lymphomagenesis in our cases.
\end{abstract}

Modern Pathology (2010) 23, 593-602; doi:10.1038/modpathol.2010.4; published online 29 January 2010

Keywords: anaplastic large cell lymphoma; Hodgkin's lymphoma; PAX5; CD30; immunohistochemistry; FISH

Cell lineage is the major criterion by which lymphomas are classified. $^{1}$ In routine clinical practice, the $\mathrm{B}$ - or T-cell origin of lymphomas is determined using immunophenotyping studies to detect lineage-associated antigens expressed by the tumor cells. Occasionally, however, loss or aberrant expression of lineage-associated antigens may

Correspondence: Dr AL Feldman, MD, Department of Laboratory Medicine and Pathology, Mayo Clinic, 200 First Street SW, Rochester, MN 55905, USA.

E-mail: feldman.andrew@mayo.edu

Received 13 November 2009; revised 17 December 2009; accepted 28 December 2009; published online 29 January 2010 present diagnostic challenges. One such challenge is the differential diagnosis between T-cell anaplastic large cell lymphoma and classical Hodgkin's lymphoma, which is a tumor of B-cell derivation.

Anaplastic large cell lymphoma and classical Hodgkin's lymphoma can show considerable morphologic overlap. ${ }^{2,3}$ Anaplastic large cell lymphomas and other peripheral T-cell lymphomas may have Reed-Sternberg-like cells and a prominent mixed inflammatory background, leading to the introduction of the term, 'Hodgkin-like' anaplastic large cell lymphoma. ${ }^{4,5}$ Conversely, some cases of classical Hodgkin's lymphoma are rich in tumor cells and have a minimal inflammatory background, 
resembling anaplastic large cell lymphoma. ${ }^{6}$ In fact, many of the tumors originally considered 'Hodgkin-like' anaplastic large cell lymphomas subsequently were reclassified as classical Hodgkin's lymphomas. ${ }^{7,8}$

In addition to their morphologic features, anaplastic large cell lymphoma and classical Hodgkin's lymphoma may show striking phenotypic overlap. Classical Hodgkin's lymphomas typically express CD30 and CD15, lack expression of multiple B-cell antigens, and may aberrantly coexpress T-cell antigens and cytotoxic proteins. ${ }^{9,10}$ Anaplastic large cell lymphomas and some peripheral T-cell lymphomas express CD30, may coexpress CD15, ${ }^{11-14}$ and often lack expression of multiple T-cell antigens despite having clonal T-cell receptor (TCR) gene rearrangements. ${ }^{15,16}$ In addition, occasional peripheral T-cell lymphomas aberrantly express B-lineage markers such as CD20 and CD79a. ${ }^{17-21}$ When present, expression of anaplastic lymphoma kinase (ALK) as a result of $A L K$ gene translocation is helpful in establishing the diagnosis of anaplastic large cell lymphoma rather than classical Hodgkin's lymphoma. ${ }^{22}$ However, approximately $45 \%$ of anaplastic large cell lymphomas are ALK negative. ${ }^{23,24}$ Correct diagnosis is critical, as classical Hodgkin's lymphoma and ALK-negative anaplastic large cell lymphoma are treated differently, and are associated with an $85 \%$ cure rate in the former and $<50 \% 5$-year overall survival in the latter. ${ }^{24,25}$

The paired box 5 (PAX5) transcription factor (Bcell-specific activating protein (BSAP)) is necessary for B-lineage commitment, ${ }^{26-28}$ and has shown excellent specificity for B-cell lineage by immunohistochemistry. ${ }^{29-33}$ PAX5 staining may be helpful in the differential diagnosis between classical Hodgkin's lymphoma and ALK-negative anaplastic large cell lymphoma, as it shows characteristic weak staining in most classical Hodgkin's lymphomas ${ }^{34}$ and 'should be negative in all cases of anaplastic large cell lymphoma', according to the 2008 WHO Classification of Tumors of Hematopoietic and Lymphoid Tissues. ${ }^{8}$

The purpose of this study was to characterize the morphologic, phenotypic, and genetic features of four cases of PAX5-positive anaplastic large cell lymphomas observed in our practice, and to compare these features with 198 additional peripheral T-cell lymphomas. Our findings indicate that PAX5 can be observed in otherwise typical anaplastic large cell lymphomas, and thus cannot be solely relied upon to distinguish anaplastic large cell lymphoma from classical Hodgkin's lymphoma. Interestingly, PAX5-positive anaplastic large cell lymphomas showed extra copies of the PAX5 gene locus, suggesting a possible mechanism for the PAX5 expression, and perhaps contributing to lymphomagenesis in these cases. Our findings support the use of a broad panel of $\mathrm{B}$ - and T-cell antigens in assigning lymphoma lineage, with additional molecular studies performed in ambiguous cases.

\section{Materials and methods}

During the period 2007 to 2009, four PAX5-positive anaplastic large cell lymphomas were identified from the hematopathology practice at Mayo Clinic, Rochester, Minnesota; 198 additional peripheral T-cell lymphomas from the years 1987 to 2009 identified from the Mayo Clinic archives were studied. All cases were classified based on 2008 WHO criteria. ${ }^{1}$

PAX5 immunohistochemistry was performed on paraffin-embedded tissue sections by pretreating in $1 \mathrm{mM}$ EDTA buffer at $\mathrm{pH} 8.0$ for $30 \mathrm{~min}$ at $97^{\circ} \mathrm{C}$ (PT Module; Lab Vision, Fremont, CA, USA) and staining for PAX5 (1:200, clone 24, BD Bioscience) on a Dako (Carpinteria, CA, USA) autostainer using the Advance detection system (Dako) with diaminobenzidine as the chromogen. Immunohistochemistry for other markers was performed as previously described $^{35}$ using antibodies shown in Table 1. Aside from CD30 and PAX5 (discussed below), immunostaining was scored as strong or weak, and designated as negative $(-$, no staining), focal $(-/+$, $<10 \%$ of tumor cells), partial $(+/-, 10-30 \%$ of tumor cells), or positive (,$+>30 \%$ of tumor cells).

Polymerase chain reaction (PCR) for TCR $\gamma$-chain and immunoglobulin gene rearrangements was performed as described previously. ${ }^{36,37}$ Fluorescence in situ hybridization (FISH) for PAX5 was performed and scored as described previously using a homebrew break-apart probe. ${ }^{38}$ In brief, DNA was isolated from bacterial artificial chromosome probes (ResGen Invitrogen; Carlsbad, CA, USA) spanning the PAX5 locus as shown in Figure 3c. Probes were labeled with SpectrumOrange-dUTP or SpectrumGreendUTP using nick translation (Abbott Molecular, Des Plaines, IL, USA) and hybridized to tissue sections. Cases with $\geq 4$ fusion signals were considered to have extra copies of the PAX5 gene locus.

Additional peripheral T-cell lymphomas were evaluated using immunohistochemistry and/or FISH as indicated above on tissue microarrays constructed from paraffin blocks as previously described. ${ }^{39}$ The study was approved by the institutional review board and biospecimens committee of Mayo Clinic.

\section{Results}

\section{Clinicopathologic Findings of PAX5-Positive Anaplastic Large Cell Lymphomas}

The clinicopathologic features of the four PAX5positive anaplastic large cell lymphomas are summarized in Table 2. There were two males and two females with an age range of 31 to 87 years. Three patients (cases 1-3) presented with lymphadenopathy and one (case 4) presented with a pathologic fracture of L4; imaging revealed masses in the neck, chest, and abdomen. Treatment data are available for three patients. One (case 1) had severe cardiac 
Table 1 Antibodies used in immunophenotypic analyses

\begin{tabular}{|c|c|c|c|}
\hline Antigen & Clone & Dilution & Source \\
\hline ALK & ALK1 & $1: 100$ & Dako (Carpinteria, CA, USA) \\
\hline BetaF1 & $8 \mathrm{~A} 3$ & $1: 100$ & Endogen (Woburn, MA, USA) \\
\hline BOB1 & TG14 & $1: 200$ & $\begin{array}{l}\text { Novocastra (Newcastle } \\
\text { upon Tyne, UK) }\end{array}$ \\
\hline CD2 & AB75 & $1: 100$ & Novocastra \\
\hline CD3 & PS1 & $1: 50$ & Novocastra \\
\hline CD4 & 4B12 & $1: 600$ & Novocastra \\
\hline CD5 & $4 \mathrm{C} 7$ & $1: 300$ & Novocastra \\
\hline CD7 & LP15 & $1: 200$ & Novocastra \\
\hline CD8 & C8/144B & $1: 100$ & Dako \\
\hline CD15 & MMA & $1: 50$ & $\begin{array}{l}\text { BD Biosciences } \\
\text { (Franklin Lakes, NJ, USA) }\end{array}$ \\
\hline CD19 & LE-CD19 & $1: 200$ & Dako \\
\hline CD20 & L26 & $1: 200$ & Dako \\
\hline CD22 & FPC1 & $1: 200$ & Novocastra \\
\hline CD30 & Ber-H2 & $1: 20$ & Dako \\
\hline CD43 & L60 & $1: 10000$ & BD Biosciences \\
\hline CD45 & $\begin{array}{l}\text { 2B11+ } \\
\mathrm{PD} 7 / 26\end{array}$ & $1: 1500$ & Dako \\
\hline CD56 & $123 \mathrm{C} 3$ & $1: 25$ & $\begin{array}{l}\text { Monosan/Caltag } \\
\text { (Burlingame, CA, USA) }\end{array}$ \\
\hline CD79a & JCB117 & $1: 50$ & Dako \\
\hline Clusterin & $41 \mathrm{D}$ & $1: 200$ & $\begin{array}{l}\text { Upstate (Lake Placid, } \\
\text { NY, USA) }\end{array}$ \\
\hline EMA & E29 & $1: 50$ & Dako \\
\hline Granzyme B & GRB-7 & $1: 100$ & Monosan/Caltag \\
\hline OCT2 & OCT-207 & $1: 100$ & Novocastra \\
\hline PAX5 & 24 & $1: 200$ & BD Biosciences \\
\hline TIA-1 & TIA-1 & $1: 200$ & $\begin{array}{l}\text { Immunotech } \\
\text { (Fullerton, CA, USA) }\end{array}$ \\
\hline
\end{tabular}

disease precluding systemic chemotherapy. He was treated with palliative radiotherapy for edema caused by bulky inguinal and pelvic adenopathy, and died 2 months later. Two patients (cases 2 and 4 ) were treated with cyclophosphamide, doxorubicin hydrochloride, oncovin, and prednisone (CHOP), and achieved a partial response at 6 months (4 cycles) and a complete response at 3 months (3 cycles), respectively.

Morphologic features in all four cases were characteristic of anaplastic large cell lymphoma (Figures 1 and 2). All showed sheets of mediumsized to large lymphocytes with variably folded or horseshoe-shaped nuclei typical of so-called 'hallmark' cells. ${ }^{40}$ Reed-Sternberg cells were absent. A sinusoidal pattern of distribution was observed in cases with lymph node material available, most prominently noted in case 2 (Figure 1e). Occasional inflammatory cells were present in the background, particularly in case 3 (Figure 2a).

All cases showed uniform, strong staining for CD30 by immunohistochemistry (Figures $1 \mathrm{~b}$ and $\mathrm{f}$ and $2 \mathrm{~b}$ and f). One case (case 4 ) was positive for ALK (predominantly cytoplasmic; Figures 2g). All cases were negative for CD3 and showed variable positivity for other T-cell antigens; of these, CD2 and CD4 were most commonly observed, with at least focal staining observed in cases 3 and 4, respectively (Figures 1c and g). Cytotoxic marker expression (TIA-1 or granzyme B) was observed at least focally in three cases. CD15 expression was observed in one
Table 2 Clinical features and results of immunohistochemistry and molecular studies in PAX5-positive anaplastic large cell lymphomas

\begin{tabular}{|c|c|c|c|c|}
\hline & Case 1 & Case 2 & Case 3 & Case 4 \\
\hline \multicolumn{5}{|l|}{ Clinical features } \\
\hline Age (year)/gender & $87 / \mathrm{M}$ & $31 / \mathrm{F}$ & $45 / F$ & $53 / \mathrm{M}$ \\
\hline Biopsy site & $\begin{array}{c}\text { Inguinal } \\
\text { lymph } \\
\text { node }\end{array}$ & $\begin{array}{c}\text { Axillary } \\
\text { lymph } \\
\text { node }\end{array}$ & $\begin{array}{c}\text { Axillary } \\
\text { lymph } \\
\text { node }\end{array}$ & $\begin{array}{c}\text { L4 } \\
\text { vertebra }\end{array}$ \\
\hline Stage & III & IIIA & Unknown & IVB \\
\hline Outcome & $\begin{array}{l}\text { Died of } \\
\text { disease }\end{array}$ & Alive, PR & Unknown & $\begin{array}{l}\text { Alive, } \\
\text { CR }\end{array}$ \\
\hline $\begin{array}{l}\text { Follow-up } \\
\text { (months) }\end{array}$ & 2 & 6 & - & 3 \\
\hline \multicolumn{5}{|l|}{ Immunohistochemistry $^{\mathrm{a}}$} \\
\hline ALK & - & - & - & + \\
\hline BetaF1 & - & ND & - & - \\
\hline BOB1 & - & - & $-/+(w)$ & - \\
\hline CD2 & + & $-/+$ & $+1-$ & - \\
\hline CD3 & - & - & - & - \\
\hline CD4 & + & + & $+1-$ & $+/-(\mathrm{w})$ \\
\hline CD5 & - & - & + & - \\
\hline CD7 & - & $-1+$ & ND & - \\
\hline CD8 & - & - & ND & - \\
\hline CD15 & - & ND & + & - \\
\hline CD19 & - & - & - & - \\
\hline CD20 & - & - & - & - \\
\hline CD22 & - & - & - & - \\
\hline CD30 & + & + & + & + \\
\hline CD43 & + & ND & $+1-$ & - \\
\hline CD45 & $+(\mathrm{w})$ & - & $+1-$ & $+(\mathrm{w})$ \\
\hline CD79a & - & - & - & - \\
\hline Clusterin & - & $-/+(w)$ & - & + \\
\hline EMA & - & $+/-(w)$ & - & + \\
\hline Granzyme B & - & ND & $-1+$ & $-1+$ \\
\hline OCT2 & - & - & $+(w)$ & $-/+(\mathrm{w})$ \\
\hline PAX5 & $+(w)$ & $+(w)$ & $+(w)$ & $+(w)$ \\
\hline TIA-1 & - & $-1+$ & $-1+$ & - \\
\hline \multicolumn{5}{|c|}{ Gene rearrangement (PCR) } \\
\hline T-cell receptor & Positive & Negative & Positive & Failed \\
\hline Immunoglobulin & Negative & Negative & Negative & Failed \\
\hline \multicolumn{5}{|l|}{ FISH } \\
\hline$\geq 4$ copies of $P A X 5$ & Yes & Yes & Yes & Failed \\
\hline
\end{tabular}

PR, partial response; CR, complete response; ND, not done; (w), weak; - , negative; $-/+,<10 \%$ of tumor cells; $+/-, 10-30 \% ;+,>30 \%$.

${ }^{\mathrm{a}}$ Immunohistochemical staining intensity was strong unless otherwise indicated.

case (case 3). Expression of EMA and clusterin was observed in two cases. PAX5 positivity was observed in $>80 \%$ of tumor cells in all cases, was solely nuclear, and was weaker than that observed in reactive $B$ cells (Figures $1 \mathrm{~d}$ and $2 \mathrm{~d}$ ), similar to the typical staining intensity of Reed-Sternberg cells in classical Hodgkin's lymphoma. Other surface B-lineage markers (CD19, CD20, CD22, and CD79a) were negative. OCT2 (POU2F2) and BOB1 (POU2AF1 or OBF1) were at least focally positive in two cases and one case, respectively.

All cases were evaluated by PCR for clonal TCR and immunoglobulin gene rearrangements. PCR failed in case 4 (decalcified specimen). Two of the remaining three cases showed clonal TCR gene rearrangements (Figures 3a and b). None showed a 

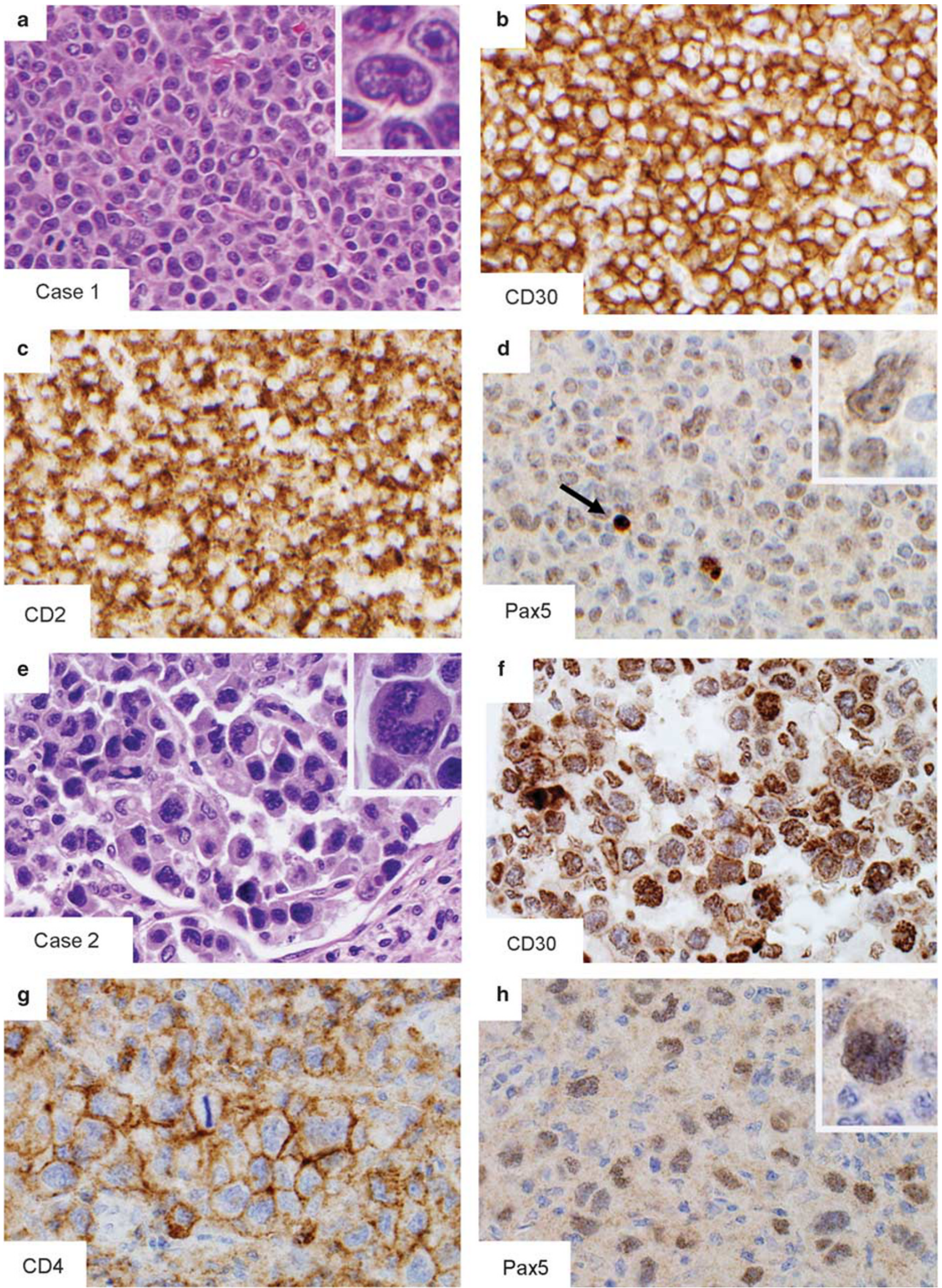

Figure 1 Histological and immunophenotypic features of PAX5-positive anaplastic large cell lymphomas (original magnification $\times 400$; insets, $\times 1000)$. (a-d) Case 1: ALK-negative anaplastic large cell lymphoma. Hematoxylin and eosin (H\&E)-stained slides of a lymph node (a) shows sheets of hallmark cells without a significant inflammatory background. The tumor cells are positive for CD30 (b) and CD2 (c). PAX5 (d) shows weak nuclear positivity in the large tumor cells, compared with strong positivity in occasional small B cells (arrow). (e-h) Case 2: ALK-negative anaplastic large cell lymphoma. H\&E-stained slides of a lymph node show hallmark cells within sinuses (e). The tumor cells are positive for CD30 (f) and CD4 (g), and are weakly positive for PAX5 (h). 

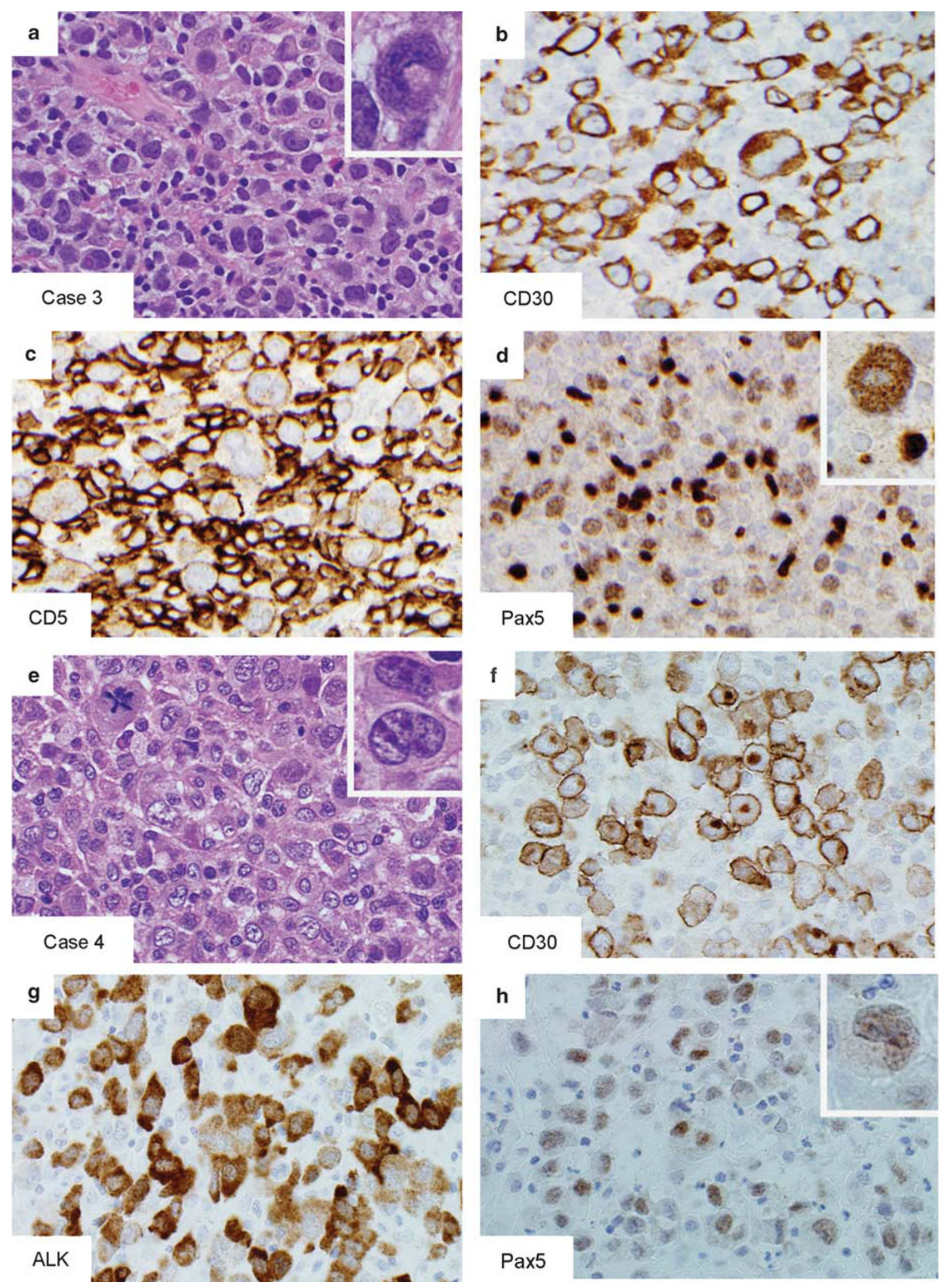

Figure 2 Histological and immunophenotypic features of PAX5-positive anaplastic large cell lymphomas, continued (original magnification $\times$ 400; insets, $\times$ 1000). (a-d) Case 3: ALK-negative anaplastic large cell lymphoma. H\&E-stained slides of a lymph node show numerous hallmark cells (a). The tumor cells are positive for CD30 (b) and CD5 (c). PAX5 (d) is more weakly positive in the tumor cells (inset, upper left) than in admixed small B cells (inset, lower right). (e-h) Case 4: ALK-positive anaplastic large cell lymphoma. H\&E-stained slides of an L4 vertebral mass show numerous hallmark cells (e). The tumor cells are positive for CD30 (f) and ALK (g), and are weakly positive for PAX5 (h). 

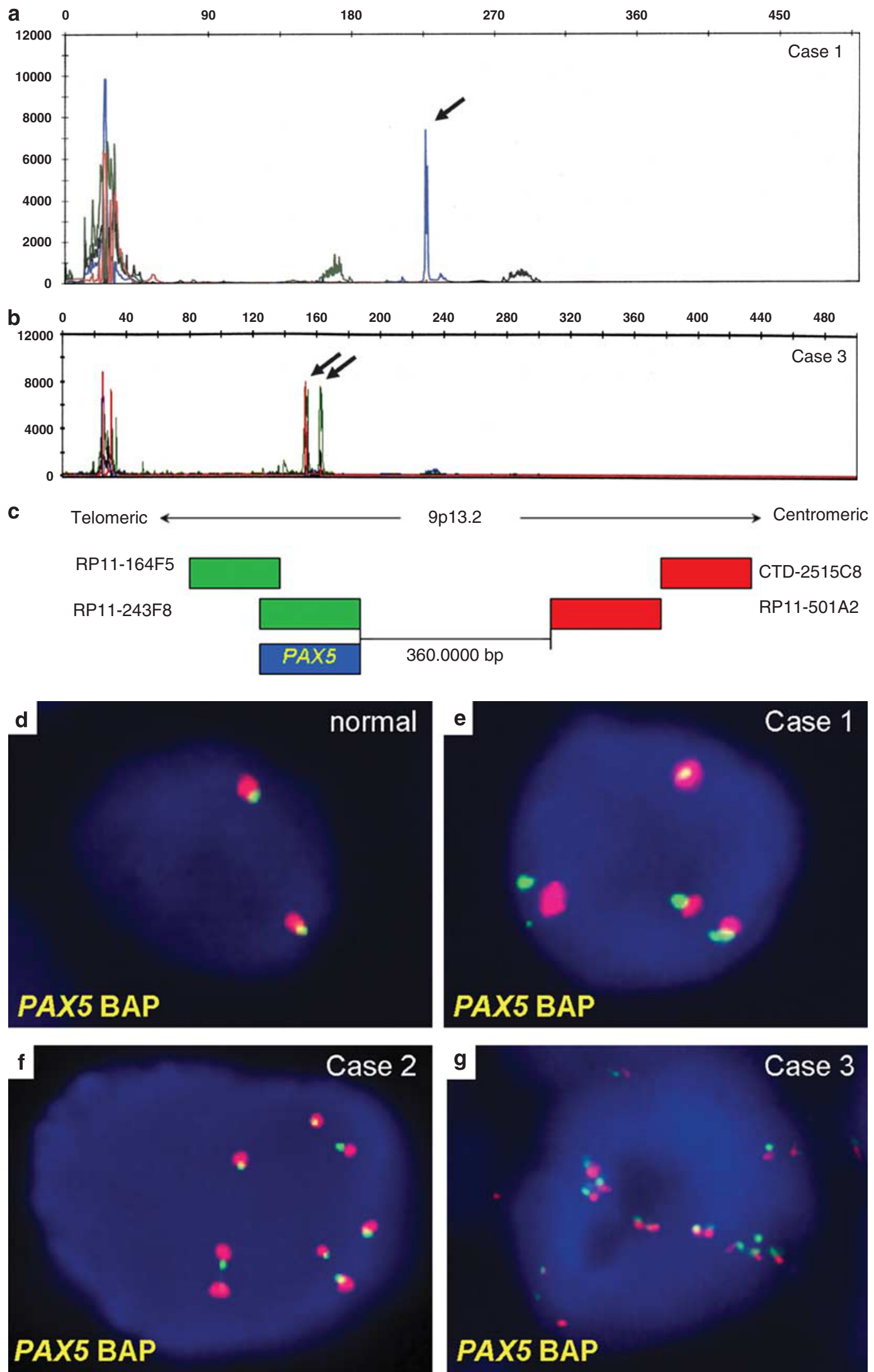

Figure 3 Molecular features of PAX5-positive anaplastic large cell lymphomas. (a,b) PCR for T-cell receptor $\gamma$-chain gene rearrangement in cases 1 (a) and 3 (b) show clonal peaks (arrows). (c) FISH was performed using a break-apart probe for the PAX5 gene locus on 9p13.2, with bacterial artificial chromosome (BAC) designations as shown. Centromeric and telomeric BACs were labeled red and green, respectively. Relative location of PAX5 is shown in blue. (d) A normal cell shows two fusion signals by FISH. (e-g) Cells from PAX5positive anaplastic large cell lymphomas show extra copies of the PAX5 gene locus. 
clonal immunoglobulin gene rearrangement. Karyotyping was not performed. FISH for the PAX5 gene locus was performed in all cases. Hybridization failed in case 4. Extra copies of PAX5 were observed in all remaining cases, with copy numbers ranging from 4 in case 1 to $>10$ in case 3 (Figures $3 \mathrm{e}-\mathrm{g}$ ). No $P A X 5$ translocation was found.

\section{Immunohistochemical and FISH Studies of Additional T-Cell Lymphomas}

PAX5 was evaluated using immunohistochemistry in 198 additional patients (117 males and 81 females; mean age, 59 years) with the following peripheral T-cell lymphoma subtypes: 25 angioimmunoblastic T-cell lymphomas; 66 anaplastic large cell lymphomas (22 ALK positive, 33 ALK negative, and 11 cutaneous); 82 peripheral T-cell lymphomas, NOS; 10 extranodal NK/T-cell lymphomas, nasal type; 6 cases of mycosis fungoides; 2 subcutaneous panniculitis-like T-cell lymphomas; 2 hepatosplenic T-cell lymphomas; 2 enteropathy-associated T-cell lymphomas; 2 T-cell large granular lymphocytic leukemias; and 1 T-cell prolymphocytic leukemia. All were negative for PAX5. Of these, 109 cases were evaluated by FISH for PAX5, and 92 showed hybridization adequate for interpretation. No PAX5 translocation was found. Of the 92 PAX5 proteinnegative peripheral T-cell lymphomas, four $(4 \%)$ had extra copies of the PAX5 gene locus. All were peripheral T-cell lymphomas, NOS. None resembled anaplastic large cell lymphoma morphologically. CD30 was negative in three and partially positive in one case $(10-30 \%$ of tumor cells). Other B-cell markers were negative.

\section{Discussion}

We report four cases of PAX5-positive T-cell anaplastic large cell lymphoma. Extra copies of the $P A X 5$ gene locus were shown in all three cases evaluable by FISH. PAX5 is a transcription factor in the paired-box-containing family, which is involved in control of organ development and tissue differentiation. ${ }^{41}$ PAX5 has an essential role in B-lymphoid lineage commitment, ${ }^{26-28}$ and is widely used as a B-cell marker in immunohistochemical evaluation of lymphoid tissues. ${ }^{30}$ Anaplastic large cell lymphomas may share morphologic and phenotypic features with B-lineage neoplasms, particularly classical Hodgkin's lymphoma. Therefore, our findings have important implications for interpreting PAX5 immunohistochemistry in lymphoma classification.

Our PAX5-positive anaplastic large cell lymphomas had clinical presentations, histological features, and phenotypes (other than PAX5 expression) that are characteristic of anaplastic large cell lymphoma, allowing definitive classification despite the unusual positivity for PAX5. Consistent with previously published data, ${ }^{42}$ the three ALK-negative cases lacked clonal immunoglobulin gene rearrangements, and two of three had clonal TCR gene rearrangements. Case 3 showed coexpression of CD15, a finding typical of classical Hodgkin's lymphoma but that may also be observed in anaplastic large cell lymphoma. ${ }^{12-14}$ The other features did not support a diagnosis of classical Hodgkin's lymphoma. There were characteristic hallmark cells with only occasional inflammatory cells observed in the background. In addition to the expression of T-cell antigens and cytotoxic markers, the tumor cells expressed BOB1 and (focally) OCT2, which are the transcription factors typically absent in classical Hodgkin's lymphoma ${ }^{43}$ Finally, the presence of a clonal TCR gene rearrangement and absence of clonal immunoglobulin gene rearrangement support the diagnosis of anaplastic large cell lymphoma in this case. Case 4 was a decalcified specimen and molecular studies were unsuccessful, but positivity for ALK assisted in confirming the diagnosis of anaplastic large cell lymphoma.

In a study of cases with overlapping features of anaplastic large cell lymphoma and classical Hodgkin's lymphoma, Tamaru et $a l^{44}$ found weak PAX5 expression in 3 of 17 ALK-negative anaplastic large cell lymphomas and 0 of 11 ALK-positive anaplastic large cell lymphomas. Although gene rearrangement studies were not performed to confirm T-cell origin, the three PAX5-positive tumors expressed both CD45 and BOB1, and two expressed EMA. These immunophenotypic features support the diagnosis of ALK-negative anaplastic large cell lymphoma rather than classical Hodgkin's lymphoma. The tumors lacked T-cell antigen expression, except for CD45RO in one case and TIA-1 in another, and were negative for OCT2. The phenotypes of our cases were similar in the intensity of PAX5 staining and variable staining for EMA. We found more consistent positivity for T-cell antigens and observed OCT2 expression in two cases; conversely, BOB1 was observed focally in only one of our cases and CD45 expression was more variable. In addition, one of our cases was ALK positive.

A single previous case of peripheral T-cell lymphoma NOS, expressing PAX5 was reported by Tzankov et al. ${ }^{45}$ No PAX5-positive cases were identified in additional peripheral T-cell lymphomas studied by Tzankov et al $(n=43),{ }^{45}$ Krenacs et al $(n=20),{ }^{31}$ Foss, et al $(n=40),{ }^{34}$ or Torlakovic et al $(n=26) .^{32}$ We did not identify any additional PAX5-positive cases in 198 peripheral T-cell lymphomas, including 66 additional anaplastic large cell lymphomas. Thus, the overall incidence of PAX5 positivity in peripheral T-cell lymphomas appears low. Nevertheless, PAX5 expression is not entirely specific for B-cell lineage in lymphomas. Furthermore, occasional non-lymphoid neoplasms express PAX5, including $\mathrm{t}(8 ; 21)$-positive acute myelogenous leukemias, small cell carcinomas, and other neuroendocrine tumors. ${ }^{30}$ 
Translocations between PAX5 and the immunoglobulin heavy chain gene (IGH@) drive PAX5 expression in mature B-cell lymphomas, ${ }^{46,47}$ In addition, PAX5 is oncogenic in $\mathrm{T}$ cells, as a reconstructed PAX5/IGH@ translocation induces T-cell lymphoblastic lymphomas in mice. ${ }^{48}$ Therefore, to analyze the mechanism for PAX5 expression in anaplastic large cell lymphoma, we performed FISH using a PAX5 break-apart probe. We did not identify PAX5 translocations. Unexpectedly, however, all (100\%) PAX5-positive anaplastic large cell lymphomas with informative FISH studies had extra copies of the PAX5 gene locus. In contrast, only $4 \%$ of PAX5-negative T-cell lymphomas had extra copies of PAX5. No PAX5-negative anaplastic large cell lymphoma had extra copies of PAX5, and previous genomic studies of anaplastic large cell lymphoma have not identified recurrent gains of $9 p$, on which $P A X 5$ resides. ${ }^{4-51}$ These findings suggest a possible association between extra copies of PAX5 and PAX5 protein expression in anaplastic large cell lymphomas. The finding of rare PAX5-negative T-cell lymphomas with extra copies of PAX5 (all peripheral T-cell lymphomas, NOS) indicates that factors besides gene dosage influence PAX5 protein expression in T-cell lymphomas. PAX5 methylation is associated with PAX5 negativity in human tumors $^{52,53}$ and might represent a mechanism by which T-cell lymphomas with extra copies of PAX5 do not express PAX5 protein. However, we did not have adequate material to assess gene methylation in our cases.

In conclusion, recognizing the existence of PAX5positive anaplastic large cell lymphomas is important to avoid incorrectly assigning B-cell lineage to these rare tumors. Specifically, PAX5 cannot always differentiate anaplastic large cell lymphoma from classical Hodgkin's lymphoma, particularly as the intensity of staining in PAX5-positive anaplastic large cell lymphomas is similar to that typically observed in classical Hodgkin's lymphoma. Diagnostic errors can be avoided by interpreting PAX5 immunohistochemistry in the context of clinical features, morphology (including both cytologic features of the tumor cells and cellular background), and a panel of B- and T-lineage-associated antibodies. Molecular studies are recommended in cases with ambiguous lineage. Extra copies of the PAX5 gene may contribute to PAX5 expression in anaplastic large cell lymphomas. Finally, as PAX5 is oncogenic in T cells, ${ }^{48}$ PAX5 expression may have contributed to lymphomagenesis in our cases.

\section{Acknowledgement}

This work was supported in part by a Career Development Award (to ALF) under Public Health Service Grant number P50 CA097274 from the University of Iowa /Mayo Clinic Lymphoma Specialized Program of Research Excellence (UI/MC
Lymphoma SPORE) and the National Cancer Institute.

\section{Disclosure/conflict of interest}

The authors declare no conflict of interest.

\section{References}

1 Swerdlow S, Campo E, Harris N, et al (eds). WHO classification of tumours of haematopoietic and lymphoid tissues. In: Bosman F, Jaffe E, Lakhani S, Ohgaki H (eds), World Health Organization Classification of Tumours, 4th edn. International Agency for Research on Cancer: Lyon, 2008.

2 Stein H, Foss HD, Durkop H, et al. CD30(+) anaplastic large cell lymphoma: a review of its histopathologic, genetic, and clinical features. Blood 2000;96: 3681-3695.

3 Vassallo J, Lamant L, Brugieres L, et al. ALK-positive anaplastic large cell lymphoma mimicking nodular sclerosis Hodgkin's lymphoma: report of 10 cases. Am J Surg Pathol 2006;30:223-229.

4 Leoncini L, Del Vecchio M, Kraft R, et al. Hodgkin's disease and CD30-positive anaplastic large cell lymphomas - a continuous spectrum of malignant disorders. Am J Pathol 1990;137:1047-1057.

5 Pileri S, Bocchia M, Baroni C, et al. Anaplastic large cell lymphoma (CD30+/Ki-1+): results of a prospective clinicopathologic study of 69 cases. Br J Haematol 1994;86:513-523.

6 Stein H, Delsol G, Pileri SA, et al. Classical Hodgkin lymphoma, introduction. In: Swerdlow S, Campo E, Harris N, Jaffe E, Pileri S, Stein H, Thiele J, Vardiman J (eds), WHO Classification of Tumours of Haematopoietic and Lymphoid Tissues, 4th edn. International Agency for Research on Cancer: Lyon, 2008, pp 326-329.

7 Jaffe ES. Anaplastic large cell lymphoma: the shifting sands of diagnostic hematopathology. Mod Pathol 2001;14:219-228.

8 Mason DY, Harris NL, Delsol G, et al. Anaplastic large cell lymphoma, ALK-negative. In: Swerdlow S, Campo E, Harris N, Jaffe E, Pileri S, Stein H, Thiele J, Vardiman J (eds), WHO Classification of Tumours of Haematopoietic and Lymphoid Tissues, 4th edn. International Agency for Research on Cancer: Lyon, 2008, pp 317-319.

9 Tzankov A, Bourgau C, Kaiser A, et al. Rare expression of T-cell markers in classical Hodgkin's lymphoma. Mod Pathol 2005;18:1542-1549.

10 Asano N, Oshiro A, Matsuo K, et al. Prognostic significance of T-cell or cytotoxic molecules phenotype in classical Hodgkin's lymphoma: a clinicopathologic study. J Clin Oncol 2006;24:4626-4633.

11 Barry TS, Jaffe ES, Sorbara L, et al. Peripheral T-cell lymphomas expressing CD30 and CD15. Am J Surg Pathol 2003;27:1513-1522.

12 Felgar RE, Salhany KE, Macon WR, et al. The expression of TIA-1+ cytolytic-type granules and other cytolytic lymphocyte-associated markers in CD30+ anaplastic large cell lymphomas (ALCL): correlation with morphology, immunophenotype, ultrastructure, and clinical features. Hum Pathol 1999;30:228-236. 
13 Gorczyca W, Tsang P, Liu Z, et al. CD30-positive T-cell lymphomas co-expressing CD15: an immunohistochemical analysis. Int J Oncol 2003;22:319-324.

14 Perkins PL, Ross CW, Schnitzer B. CD30-positive, anaplastic large-cell lymphomas that express CD15 but lack CD45. A possible diagnostic pitfall. Arch Pathol Lab Med 1992;116:1192-1196.

15 Foss HD, Anagnostopoulos I, Araujo I, et al. Anaplastic large-cell lymphomas of T-cell and null-cell phenotype express cytotoxic molecules. Blood 1996;88:4005-4011.

16 Bonzheim I, Geissinger E, Roth S, et al. Anaplastic large cell lymphomas lack the expression of T-cell receptor molecules or molecules of proximal T-cell receptor signaling. Blood 2004;104:3358-3360.

17 Quintanilla-Martinez L, Preffer F, Rubin D, et al. CD20+ T-cell lymphoma. Neoplastic transformation of a normal T-cell subset. Am J Clin Pathol 1994;102: 483-489.

18 Blakolmer K, Vesely M, Kummer JA, et al. Immunoreactivity of B-cell markers (CD79a, L26) in rare cases of extranodal cytotoxic peripheral T- (NK/T-) cell lymphomas. Mod Pathol 2000;13:766-772.

19 Yao X, Teruya-Feldstein J, Raffeld M, et al. Peripheral T-cell lymphoma with aberrant expression of CD79a and CD20: a diagnostic pitfall. Mod Pathol 2001;14: 105-110.

20 Went P, Agostinelli C, Gallamini A, et al. Marker expression in peripheral T-cell lymphoma: a proposed clinical-pathologic prognostic score. J Clin Oncol 2006; 24:2472-2479.

21 Sen F, Kang S, Cangiarella J, et al. CD20 positive mycosis fungoides: a case report. J Cutan Pathol 2008; 35:398-403.

22 Wellmann A, Otsuki T, Vogelbruch M, et al. Analysis of the $t(2 ; 5)$ (p23;q35) translocation by reverse transcription-polymerase chain reaction in CD 30+ anaplastic large-cell lymphomas, in other non-Hodgkin's of T-cell phenotype, and in Hodgkin's disease. Blood 1995;86:2321-2328.

23 Vose J, Armitage J, Weisenburger D. International peripheral T-cell and natural killer/T-cell lymphoma study: pathology findings and clinical outcomes. J Clin Oncol 2008;26:4124-4130.

24 Savage KJ, Harris NL, Vose JM, et al. ALK- anaplastic large-cell lymphoma is clinically and immunophenotypically different from both ALK+ ALCL and peripheral T-cell lymphoma, not otherwise specified: report from the International Peripheral T-Cell Lymphoma Project. Blood 2008;111:5496-5504.

25 Diehl V, Engert A, Re D. New strategies for the treatment of advanced-stage Hodgkin's lymphoma. Hematol Oncol Clin North Am 2007;21:897-914.

26 Nutt SL, Heavey B, Rolink AG, et al. Commitment to the B-lymphoid lineage depends on the transcription factor Pax5. Nature 1999;401:556-562.

27 Mikkola I, Heavey B, Horcher M, et al. Reversion of B cell commitment upon loss of Pax5 expression. Science 2002;297:110-113.

28 Cobaleda C, Jochum W, Busslinger M. Conversion of mature $\mathrm{B}$ cells into $\mathrm{T}$ cells by dedifferentiation to uncommitted progenitors. Nature 2007;449:473-477.

29 Mhawech-Fauceglia P, Saxena R, Zhang S, et al. Pax-5 immunoexpression in various types of benign and malignant tumors: a high-throughput tissue microarray analysis. J Clin Pathol 2007;60:709-714.

30 Feldman AL, Dogan A. Diagnostic uses of Pax5 immunohistochemistry. Adv Anat Pathol 2007;14:323-334.
31 Krenacs L, Himmelmann AW, Quintanilla-Martinez L, et al. Transcription factor B-cell-specific activator protein (BSAP) is differentially expressed in B cells and in subsets of B-cell lymphomas. Blood 1998;92: 1308-1316.

32 Torlakovic E, Torlakovic G, Nguyen PL, et al. The value of anti-pax-5 immunostaining in routinely fixed and paraffin-embedded sections: a novel pan pre-B and B-cell marker. Am J Surg Pathol 2002;26:1343-1350.

33 Tiacci E, Pileri S, Orleth A, et al. PAX5 expression in acute leukemias: higher B-lineage specificity than CD79a and selective association with $\mathrm{t}(8 ; 21)$-acute myelogenous leukemia. Cancer Res 2004;64:7399-7404.

34 Foss HD, Reusch R, Demel G, et al. Frequent expression of the B-cell-specific activator protein in ReedSternberg cells of classical Hodgkin's disease provides further evidence for its B-cell origin. Blood 1999;94: 3108-3113.

35 Kurtin PJ, Hobday KS, Ziesmer S, et al. Demonstration of distinct antigenic profiles of small B-cell lymphomas by paraffin section immunohistochemistry. Am J Clin Pathol 1999;112:319-329.

36 Morice WG, Katzmann JA, Pittelkow MR, et al. A comparison of morphologic features, flow cytometry, TCR-Vbeta analysis, and TCR-PCR in qualitative and quantitative assessment of peripheral blood involvement by Sezary syndrome. Am J Clin Pathol 2006;125: 364-374.

37 McClure RF, Kaur P, Pagel E, et al. Validation of immunoglobulin gene rearrangement detection by PCR using commercially available BIOMED-2 primers. Leukemia 2006;20:176-179.

38 Remstein ED, Law M, Mollejo M, et al. The prevalence of IG translocations and $7 q 32$ deletions in splenic marginal zone lymphoma. Leukemia 2007;22: 1268-1272.

39 Feldman AL, Law M, Grogg KL, et al. Incidence of TCR and TCL1 gene translocations and isochromosome $7 q$ in peripheral T-cell lymphomas using fluorescence in situ hybridization. Am J Clin Pathol 2008;130: 178-185.

40 Benharroch D, Meguerian-Bedoyan Z, Lamant L, et al. ALK-positive lymphoma: a single disease with a broad spectrum of morphology. Blood 1998;91:2076-2084.

41 Walther C, Guenet JL, Simon D, et al. Pax: a murine multigene family of paired box-containing genes. Genomics 1991;11:424-434.

42 Tan BT, Seo K, Warnke RA, et al. The frequency of immunoglobulin heavy chain gene and T-cell receptor gamma-chain gene rearrangements and Epstein-Barr virus in ALK+ and ALK- anaplastic large cell lymphoma and other peripheral T-cell lymphomas. J Mol Diagn 2008;10:502-512.

43 Loddenkemper C, Anagnostopoulos I, Hummel M, et al. Differential Emu enhancer activity and expression of BOB.1/OBF.1, Oct2, PU.1, and immunoglobulin in reactive B-cell populations, B-cell non-Hodgkin lymphomas, and Hodgkin lymphomas. J Pathol 2004; 202:60-69.

44 Tamaru J, Tokuhira M, Nittsu N, et al. Hodgkin-like anaplastic large cell lymphoma (previously designated in the REAL classification) has same immunophenotypic features to classical Hodgkin lymphoma. Leuk Lymphoma 2007;48:1127-1138.

45 Tzankov AS, Went PT, Munst S, et al. Rare expression of BSAP (PAX-5) in mature T-cell lymphomas. Mod Pathol 2007;20:632-637. 
46 Busslinger M, Klix N, Pfeffer P, et al. Deregulation of PAX-5 by translocation of the Emu enhancer of the IgH locus adjacent to two alternative PAX-5 promoters in a diffuse large-cell lymphoma. Proc Natl Acad Sci USA 1996;93:6129-6134.

47 Poppe B, De Paepe P, Michaux L, et al. PAX5/IGH rearrangement is a recurrent finding in a subset of aggressive B-NHL with complex chromosomal rearrangements. Genes Chromosomes Cancer 2005;44:218-223.

48 Souabni A, Jochum W, Busslinger M. Oncogenic role of Pax5 in the T-lymphoid lineage upon ectopic expression from the immunoglobulin heavy-chain locus. Blood 2007;109:281-289.

49 Salaverria I, Bea S, Lopez-Guillermo A, et al. Genomic profiling reveals different genetic aberrations in systemic ALK-positive and ALK-negative anaplastic large cell lymphomas. Br J Haematol 2008;140:516-526.
50 Mao X, Orchard G, Lillington DM, et al. Genetic alterations in primary cutaneous CD30+ anaplastic large cell lymphoma. Genes Chromosomes Cancer 2003;37:176-185.

51 Zettl A, Rudiger T, Konrad MA, et al. Genomic profiling of peripheral T-cell lymphoma, unspecified, and anaplastic large T-cell lymphoma delineates novel recurrent chromosomal alterations. Am J Pathol 2004; 164:1837-1848.

52 Lazzi S, Bellan C, Onnis A, et al. Rare lymphoid neoplasms coexpressing B- and T-cell antigens. The role of PAX-5 gene methylation in their pathogenesis. Hum Pathol 2009;40:1252-1261.

53 Palmisano WA, Crume KP, Grimes MJ, et al. Aberrant promoter methylation of the transcription factor genes PAX5 alpha and beta in human cancers. Cancer Res 2003;63:4620-4625 